\title{
Mudanças no comportamento e desenvolvimento do escolar a partir do cuidado à família
}

\author{
Changes in scholar's behavior and development through the family care \\ Cambios en el comportamiento y desarrollo del escolar a partir del cuidado de la familia
}

\section{Ana Carmen Alonso Nachtigall Schmitt', Regina Gema Santini Costenaro', Rosiane Filipin Rangel', Carla Lizandra de Lima Ferreira', Maria Ribeiro Lacerda"}

'Centro Universitário Franciscano, Área de Ciências Biológicas e da Saúde, Curso de Enfermagem. Santa Maria-RS, Brasil. "Universidade Federal de Santa Maria, Programa de Pós-Graduação em Enfermagem. Santa Maria-RS, Brasil. Universidade Federal do Paraná, Programa de Pós-Graduação em Enfermagem. Curitiba-PR, Brasil.

\section{Submissão: 21-08-2012Ａprovação: 22-07-2013}

\section{RESUMO}

Objetivou-se descrever as contribuições da enfermagem nas relações familiares de escolares que apresentam alterações no comportamento e no rendimento escolar. Pesquisa-ação, fundamentada no método da problematização, em que se fez uso do Método do Arco, implementado em cinco etapas: observação da realidade, pontos-chave, teorização, hipóteses de solução e aplicação à realidade. Foi realizada em uma escola municipal localizada na região oeste da cidade de Santa Maria-RS. Participaram da amostra 25 famílias de escolares, no período de março a maio de 2012. Verificou-se que o sonho de ter a família ideal existe, porém a realidade vivenciada ainda é permeada por inúmeras dificuldades e requer modificações. Cuidar das relações da família mostra-se como uma possibilidade da sociedade desenvolver-se mais dignamente, considerando a potente influência que essa exerce no desenvolvimento e na formação do caráter das pessoas.

Descritores: Saúde Escolar; Família; Enfermagem.

\section{ABSTRACT}

This study aimed to describe the contributions of nursing in the family relationships of scholars who have changes in school behavior and performance. It's an action research, based on the questioning method, using the Arc Method, implemented in five stages: reality observation, key-points, theory, possible solutions, and application to reality. The research happened in a municipal school, located in the west of Santa Maria-RS. 25 scholars' families participated in the sample, during March to May of 2012. It was noticed that the dream of having an ideal family exists, but the lived reality is still permeated by a lot of difficulties and require modifications. Thus, take care of the family relationships shows up as a possibility of society to develop worthily, considering the powerful influence it has on the people character development and formation.

Key words: School Health; Family; Nursing.

\section{RESUMEN}

El objetivo de este estudio fue describir las contribuciones de la enfermería en las relaciones familiares de los niños que experimentan cambios en el comportamiento y rendimiento escolar. Se trata de una investigación-acción, basada en el método de problematización, utilizando el Método de Arco, implementado en cinco etapas: observación de la realidad, puntos-clave, teoría, soluciones posibles y aplicación a la realidad. Este estudio se realizó en una escuela municipal, ubicada en la ciudad occidental de Santa María-RS. Participaron de la amuestra 25 familias de los estudiantes, en el período de marzo a mayo de 2012. Se notó que el sueño de tener la familia ideal existe, pero la realidad en que viven todavía está permeada por muchas dificultades y requieren modificaciones. Así, hacerse cargo de las relaciones familiares se muestra como una posibilidad de la sociedad desarrollarse más dignamente, teniendo en cuenta la posible influencia que esto ejerce sobre el desarrollo y formación del carácter de las personas.

Palabras clave: Salud Escolar, Familia, Enfermería. 


\section{INTRODUÇÃO}

O Programa Saúde na Escola (PSE) tem como perspectiva a inter-relação da educação com outros saberes e ciências, em especial da área de saúde ${ }^{(1)}$. Vem potencializar as relações familiares, as quais, em alguns momentos, também apresentam limitações para resolver determinadas situações.

Atualmente o espaço escolar deve ser compreendido como um cenário de convivência de crianças e adolescentes, relacionando efetivamente suas respectivas famílias, os professores e a comunidade. A promoção da saúde nesse meio é de grande relevância, atuando principalmente na constituição do conhecimento da pessoa com uma visão crítica, estimulando-a à autonomia, ao exercício de direitos e deveres, com atitudes mais saudáveis relacionadas às condições de sua saúde e qualidade de vida(2). Esse é um desafio para profissionais de saúde e educação, seus interlocutores, usuários, gestores e formuladores de políticas sociais, além de movimentos sociais, suas representações populares, acadêmicas e de serviços públicos e privados ${ }^{(3)}$.

Os escolares não aprendem apenas no cenário escolar, mas também em outros espaços sociais. Todavia, não há dúvida quanto à função básica da escola como espaço de ensinar e aprender e também de mediar as relações da família com aspectos da saúde, que pode consolidar a prática que congrega o sujeito a participar, interagir e constituir no coletivo um novo saber.

Reconhecer as diferenças individuais e coletivas favorece a criação de diferentes espaços de promoção da saúde, incluindo a família, a comunidade, o serviço de saúde e a escola ${ }^{(4)}$.

As famílias são obra da sociedade em que estão inseridas e a história vivida por seus membros, bem como os papéis e funções que desempenham, têm íntima relação com a estrutura política, econômica, social e cultural que as constitui( ${ }^{(5)}$.

Mediante o exposto, questiona-se: como a enfermagem pode contribuir para as relações das famílias de escolares que apresentam alterações no comportamento e no rendimento escolar? Assim, este estudo objetivou descrever as contribuições da enfermagem nas relações das famílias de escolares que apresentam alterações no comportamento e no rendimento escolar.

\section{METODOLOGIA}

Pesquisa-ação fundamentada no método da problematização, em que foi utilizado um esquema denominado Método do Arco, que considera como premissa da educação a realidade circundante ao indivíduo, suas vivências, experiências e conhecimentos, tendo como finalidade a transformação do contexto social. A metodologia da problematização enfatiza que os problemas a serem estudados precisam valer-se de um cenário real, além disso, é também, uma das manifestações do construtivismo na educação. Enfoca a transformação social, a conscientização de direitos e deveres do cidadão, mediante uma educação libertadora e emancipatória(2).

Originária do pensamento freireano, a metodologia da problematização foi proposta inicialmente por Bordenave e
Pereira ${ }^{(6)}$ e revelou-se uma estratégia inovadora na área educacional. Esses autores utilizaram um esquema elaborado por Charles Maguerez, denominado Método do Arco, que tem seu ponto de partida na realidade, seguindo uma trajetória de observações sobre um problema, reflexões, teorizações, hipóteses de solução e proposições para voltar à realidade e poder transformá-la.

A pesquisa foi realizada nos meses de março a maio de 2012 em uma escola municipal localizada na região oeste da cidade de Santa Maria - RS. Participaram 25 famílias de escolares que atenderam aos critérios de inclusão: situação extrema de vulnerabilidade, dificuldades de aprendizagem ou situação de risco para evasão escolar.

Os dados foram coletados por meio de um diário de campo em que foram descritos as discussões e os depoimentos das famílias no decorrer dos encontros, os quais foram previamente agendados e ocorreram em uma sala de aula da referida escola. Os encontros foram realizados e coordenados pela própria pesquisadora após autorização da escola. Um convite foi enviado às famílias para a primeira reunião e, nesta, o cronograma dos demais encontros foi construído em conjunto.

Para melhor compreensão do perfil dos participantes, utilizou-se a estatística descritiva. Para análise dos resultados dos encontros foram seguidas as cinco etapas descritas no Método do Arco de Maguerez ${ }^{(6-7)}$. A fim de manter o anonimato das famílias participantes, os depoentes receberam nomes de flores.

As questões éticas foram seguidas conforme consta na Resolução no 196/1996 que orienta a ética na pesquisa com seres humanos ${ }^{(8)}$. Cada participante assinou o Termo de Consentimento Livre e Esclarecido. O projeto foi aprovado pelo Comitê de Ética do Centro Universitário Franciscano (UNIFRA) com registro na CONEP n 1246 e Registro CEP/UNIFRA $n^{\circ} 410.2011 .2$.

\section{IMPLEMENTAÇÃO DO MÉTODO DO ARCO DE MAGUEREZ}

\section{$1^{\text {a }}$ Etapa - Observação da realidade social}

Para a observação da realidade vivida pelas famílias, os encontros assumiram a forma de rodas de conversa, a fim de proporcionar a interação entre participantes e pesquisadores. No primeiro encontro, após a explanação do objetivo principal, a primeira expressão das mães foi de curiosidade, alegria e entusiasmo, por encararem tais reuniões como uma oportunidade de expressar a realidade vivida dentro de seus lares, com anseios, preocupações e lutas diárias. No decorrer de dez encontros, prevaleceu a presença de mulheres (mães), na maioria das vezes acompanhadas de seus filhos. O comparecimento só de mulheres permitiu que pudessem expor com maior liberdade o cotidiano vivido dentro da família.

Foi possível observar a imensa necessidade de acolhimento que estas mulheres sentiam, por falta de alguém para ouvi-las, o distanciamento conjugal, a sobrecarga de trabalho resultante de afazeres domésticos, trabalho fora do lar e cuidado com os filhos. Muitas vezes sentem-se insuficientes, pois a demanda de tempo nos afazeres ao longo do dia impossibilita uma conversa de qualidade com os filhos, aumentando o distanciamento. Existe dificuldade de diálogo entre mãe e filhos 
e demais componentes da família e baixa autoestima entre as mulheres. Algumas se isolam do convívio externo, passam sozinhas ou cuidando de seus filhos e netos em seus lares.

A história de vida da maioria (95\%) das participantes mostrou-se repleta de lutas e desafios, $80 \%$ relataram ter depressão e fazer uso de medicações controladas. A dificuldade para se relacionar com os filhos foi manifestada por $90 \%$ das mães, sendo que justificaram essa dificuldade por não terem abertura e não entenderem seus filhos. Além do sofrimento que sentem ao vivenciar situações em que os filhos estão agindo de maneira inadequada e com pouco afeto, sofrem quando os filhos preferem a ajuda de estranhos em detrimento de sua ajuda. Observa-se que apesar de habitarem no mesmo local, existe falta de vínculo entre os membros da família.

Eu orientei, ensinei, ela teve uma filha e eu ajudei, ela engravidou de novo, o cara não quis assumir e eu assumi, estou com as duas filhas dela. Qual é a mãe que vai se colocar nesse lugar e abrir mão de viver?(Violeta).

Eu disse que quando ela começasse a estudar, eu ia voltar a estudar de novo, aí ela teve a pequena e eu pensei: Bom, então vou dar mais um tempo, né. Aí depois ela engravidou de novo e eu disse: Bom, ela esta grávida, vou deixar para o ano, né. Ela vai tomar juízo, vai cuidar das filhas, cuidar da casa de noite para mim poder estudar. Não fez nada disso. (Rosa).

Eu virei um ano em que eu tive que vender a minha casa de 8 peças, construída com sacrifício, por 4 mil, pagando prestação de 200, agora por uma outra do mesmo tamanho quase, né, que vai sair 7 mil. Eu disse para ela: Eu pago o leiteiro, eu pago fralda, eu pago remédio, eu dou alimento, eu dou carinho, eu dou amor que a mãe tinha que dar.. A minha estrutura já esta ficando balançada, o meu sistema nervoso já está começando a balançar. (Girassol).

Larguei o marido, estou vivendo bem, criando meu filho. Quando ele quer um brinquedo, eu levo ele lá no $R \$ 1,99$, dou e digo: Não é igual, mas é o que a mãe pode te dar. (Bromélia).

É triste ver que eles preferem muitas vezes conversar e pedir ajuda pra um estranho do que para a própria mãe. (Orquídea).

Comemorar o dia das mães pra mim é um momento de tristeza e de alegria ao mesmo tempo. Porque tem dias que não me sinto mãe de verdade, pois não consigo dar o que meu filho precisa. Meu marido não se preocupa com isso. (Margarida).

As mães carregam consigo uma grande tristeza, sendo que os encontros possibilitaram que compartilhassem o que ocultavam em seu interior e ressaltassem a importância de valorizar as pessoas no núcleo familiar. O choro foi manifestado por $100 \%$ das mães quando verbalizaram a falta que sentiam do pai, da mãe, do irmão que faleceu. Muitas vezes disseram que chegam ao final do dia e estão tão cansadas que acabam não conversando, não tendo tempo de dizer às pessoas da casa o quanto são importantes para elas, não se abraçam e nem se sentam junto para conversar. Após a observação da realidade vivenciada pelas pessoas da família, foi possível passar para a segunda etapa, na qual se identifica e dá-se nome ao problema encontrado, a fim de estudá-lo.

\section{$2^{\text {a }}$ Etapa - Pontos-chave}

Foi possível identificar alguns dos principais problemas encontrados nas famílias participantes, sendo estes: falta de diálogo no núcleo familiar e social, potencializando a desintegração entre pais e filhos; baixa autoestima, tristeza, depressão, necessidade de serem ouvidas e amadas; relacionamento conjugal desestruturado e desvalorização do cônjuge; sentimento de perda e de ser insuficiente com os filhos; dificuldade em expressar sentimentos de amor e afeto pelas pessoas queridas e da família, dependência química e DST na família.

\section{$3^{\text {a }}$ Etapa - Teorização}

Nessa etapa expõe-se o estudo acerca dos pontos-chave. É o momento da investigação, referente ao que os autores abordam em relação ao problema, passando para uma perspectiva mais científica. Nos encontros, a teorização ocorreu de maneira a colocar o problema e, partindo das opiniões, foram buscadas soluções e também exemplificados os casos de famílias e as relações em que ocorreram as mesmas dificuldades e as pessoas nelas envolvidas conseguiram superar. $\mathrm{Ou}$ seja. As discussões versavam sobre resiliência, ou seja, buscar no conflito ou no problema a oportunidade de crescimento pessoal e social. Os temas teorizados foram:

\section{Falta de diálogo no núcleo familiar e social, potencializan- do a desintegração entre pais e filhos}

A família pode ser considerada uma verdadeira incubadora, cenário em que o caráter, o comportamento e os demais valores e princípios são formados. O Programa Nacional de Saúde Escolar $^{(9)}$ salienta que a família é a primeira escola da criança e objetiva seu bem-estar físico, psicológico, social, afetivo e moral. Para ser efetiva e eficaz, a vida familiar depende de condições para a sustentação dos vínculos afetivos diariamente.

Percebe-se a que família ideal é desejada pelas pessoas, porém, na realidade do cenário familiar, observam-se famílias desestruturadas, as quais não oferecem bases firmes para um bom desenvolvimento de seus componentes. Considera-se que as famílias que apresentam características disfuncionais podem transmitir aos filhos modelos de comportamento inadequados $^{(10)}$.

\section{Baixa autoestima, tristeza, depressão, necessidade de se- rem ouvidas e amadas}

A autoestima é uma das características das pessoas mais felizes. Pode estar associada tanto a resultados negativos, quanto positivos. Também pode ser definida como a avaliação afetiva do valor, apreço ou importância que cada um faz de si próprio ${ }^{(11)}$. 
Um fator que influencia a baixa autoestima das mulheres é o desvalor expressado pelos cônjuges, fazendo com que não se sintam valorizadas na família, acarretando problemas que interferem na estruturação conjugal e familiar.

\section{Relacionamento conjugal desestruturado e desvalorização do cônjuge}

A conjugalidade é uma síntese de aspectos positivos e negativos vividos a dois, dentre os quais se destaca a falta de estima no casamento, uma forma de decadência da convivência construtiva amorosa, que se refere à falta de expressão afetiva e desvalorização da singularidade da pessoa. Isso fragiliza a convivência a dois, degradando a vida conjugal, na medida em que não há possibilidade da liberdade de ser quem se é no convívio familiar ${ }^{(12)}$.

O modo como são expressos os sentimentos no relacionamento a dois pode influenciar a forma como a pessoa se vê. Ambos os cônjuges esperam que sejam supridas suas necessidades, tanto afetivas, quanto físicas. Quando essa reciprocidade amorosa não ocorre, ocorre a solidão emocional, a qual pode ser acompanhada por um sentimento de angústia e tristeza que, ao se aprofundar, leva a pessoa ao sofrimento, vivido sempre como uma experiência desagradável ${ }^{(12)}$. A desvalorização da pessoa pode ser geradora de inúmeros sentimentos, dentre eles o de insuficiência para com os familiares.

\section{Sentimento de perda e de ser insuficiente com os filhos}

No que se refere ao papel da mãe, pode-se verificar que, independentemente das transformações que a família vem sofrendo, as funções de cuidadora do lar e dos filhos permanecem vinculados à mulher ${ }^{(13)}$.

A crise econômica a que está sujeita a família induz a ida de seus filhos para a rua, a fim de ajudar no orçamento familiar. Essa situação, que era temporária, pode se estender, levando o convívio entre pais e filhos a se tornar cada vez mais distante ${ }^{(14)}$.

A perda ou o rompimento dos vínculos na família produz sofrimento e leva a pessoa à descrença de si mesmo, tornando-a frágil e com autoestima reduzida. Com a incorporação de um sentimento desagregador, desfaz-se o que pode haver de mais significativo para o ser humano: a capacidade de amar e de se sentir amado ${ }^{(14)}$.

\section{Dificuldade em expressar sentimentos de amor e afeto pe-} las pessoas da família

É importante que as conversas entre pais e filhos sejam constantemente estimuladas e que sejam de realizadas de forma aberta, um tentando compreender o outro. Essa interação propicia o rompimento da barreira do distanciamento, além de facilitar as demonstrações de afeto.

A família pode ser fonte de afeto e também de conflito, o que significa considerá-la em seu movimento, sua vulnerabilidade e sua fragilidade, ampliando o foco sobre ela. Não visualizá-la de forma fragmentada, mas trabalhar com o conjunto que a compõe, se um membro está precisando de assistência, sua família também estará(14).

A presença de diálogo e compreensão na família fortalece os laços afetivos, evitando que seus componentes busquem refúgio fora do lar. Pois, quando isso não ocorre, as pessoas podem vir a sentir-se mais acolhidas na rua do que em seu lar, isso propicia a diversas situações de vulnerabilidade, dentre elas, as drogas e DSTs.

\section{Dependência química e DSTs na família}

A Síndrome da Imunodeficiência Adquirida (AIDS) é a mais grave e conhecida das DSTs e representa um dos maiores problemas de Saúde Pública da atualidade ${ }^{(15)}$.

Entre os portadores da doença, ressalta-se que o medo, o preconceito, o abandono, a culpa e a exclusão ainda são constantes. Sendo assim, é preciso encontrar estratégias para auxiliá-los e às suas famílias em seus processos de enfrentamento, aceitação e naturalização da situação. Por isso é preciso que os profissionais de saúde trabalhem de maneira efetiva nos aspectos psíquicos, emocionais e sociais amenizando o sofrimento do portador e sua família(16).

\section{$4^{a}$ etapa - Hipóteses de solução}

Pensando em promover melhoras nas situações problemas encontradas, foram desenvolvidas ações que propiciaram reflexos resolutivos, desencadeando soluções nas famílias participantes. Tais ações podem ser visualizadas a seguir: festa de comemoração, promovendo os valores da família; oficina para melhora da autoestima nas mulheres; oficina do autocuidado: prevenindo DSTs/Aids; encontro Terapia do Abraço e comemoração do Dia Internacional da Mulher e do Dia das Mães.

\section{$5^{\mathrm{a}}$ etapa - Aplicação à realidade: execução da Ação}

Completa-se assim o arco de Maguerez, levando a pequenas transformações no cotidiano das pessoas, que podem ser desencadeadoras de grandes repercussões no desenvolver do escolar, considerando que família pode ser a maior fonte de influência em sua formação.

A seguir, alguns depoimentos das mães, referentes aos encontros e algumas modificações no cotidiano, observadas por elas após a reflexão sobre os benefícios que esses encontros trouxeram a elas e suas famílias.

Sabe que depois que comecei a entrar mais tarde na aula para conversar sobre mulher, eu até me acho mais bonita. (Bromélia).

Aquele dia que eu participei, eu sai daqui me sentindo bem aliviada, eu consegui me abrir, eu não tinha com quem me abrir, com quem falar os meus problemas, eu achei ótimo, estão de parabéns. (Crisântemo).

Eu agradeço também a Deus por esse momento e também pelos momentos que nós já passamos e por vocês (pesquisadores) estarem aqui conosco. (Hortência).

Eu agradeço do fundo do coração por eu ter conhecido vocês e eu ter conhecido essa escola maravilhosa. E tenho muito a agradecer a Deus também pela saúde e pela ajuda que vocês deram para minha filha no hospital quando nasceu, fico muito orgulhosa. (Amor Perfeito). 
A minha filha, ela é hostil, mas ela mudou o jeito dela, sabe, principalmente depois daquele encontro em que foi discutido sobre a tristeza e que teve a terapia do abraço. Nos encontros que ela conversa com vocês, ela volta para casa paciente, então aquilo passa por uns dias. Daí quando ela quer ficar agressiva, está chegando a próxima reunião, aí o que está errado nós vamos corrigir. (Chuva de Prata).

Antes a minha filha vivia falando que eu não ensinava ela a fazer nada. Eu disse: Tu queres fazer, então vou te ensina a cozinhar. Está servindo de terapia, está sendo uma maravilha, porque é coisa que a gente faz juntas. (Dália).

Os encontros são muito bons pra gente, longe do marido, entre mulheres, a gente consegue conversar o problema, consegue interagir uma com a outra. Junto com o marido e com os filhos tu não consegues te abrir. (Copo de Leite).

Tem sido muito bom para poder conversar, explicar a situação do que se passa, discutir os problemas que a gente enfrenta no dia-a-dia. (Azaléa).

Eu suspeitava que a minha filha estivesse namorando escondida. Em vez de bater boca ou partir para a agressão, eu mostrei para ela o dinheiro que estava juntando para sua festa de 15 anos, querendo dizer que me importo com ela e que gostaria de realizar seu desejo, estava lutando para isto, daí ela encheu os olhos de lágrimas. (Samambaia).

Finalizando, a aplicação à realidade é um momento de ação, de prática, de agir sobre aquela realidade. Salienta-se que nem sempre são possíveis grandes transformações, mas toda e qualquer mudança de pensamento, de forma de perceber, no modo de pensar, na maneira de lançar criticamente olhares inovadores ao que está posto deve ser considerada positiva e como possível solução ao problema ${ }^{(6)}$.

\section{CONSIDERAÇÕES FINAIS}

Este estudo permitiu constatar que a enfermagem possui conhecimentos para auxiliar nas relações de família de escolares que apresentam dificuldades no desenvolvimento escolar por meio de diálogo, orientações, esclarecimentos de dúvidas e encaminhamentos às redes de cuidado. As intervenções de enfermagem aqui descritas foram possíveis devido à flexibilidade das relações e às diversas ferramentas de apoio que o sistema de saúde oferece.

Percebeu-se que sonho de ter a família ideal existe no interior das pessoas que compõem a família, porém a realidade vivenciada por elas ainda é permeada por inúmeras dificuldades e requer modificações para que o convívio familiar seja como o desejado. Como resultado dos encontros, constatou-se que o vínculo familiar necessita ser fortalecido e renovado a cada dia pelas pessoas que compõem o núcleo familiar, o que foi considerado um desafio para cada uma das participantes.

Considera-se que a aceitação das famílias participantes foi boa, bem como sua persistência no decorrer dos encontros, que exterioriza o anseio e a busca por transformação pessoal. Espera-se que esta seja estendida a todas as pessoas que compõe o círculo familiar. Os encontros repercutiram em pequenas transformações no cotidiano das famílias e refletiram em melhora do convívio familiar, principalmente no relacionamento entre mãe e filhos.

O cenário escolar pode ser entendido como um laboratório de promoção da saúde e por isso a enfermagem e as demais ciências da saúde devem preenchê-lo por meio de projetos que discutam o autocuidado e a promoção para o viver saudável. As lacunas e os problemas que envolvem o cenário escolar tornam-no um campo extremamente vasto para ações de saúde das diferentes áreas do saber, que requer a contribuição de novos pesquisadores, tendo em vista sua complexidade e a diversidade de sujeitos que o compõem: alunos, professores, famílias e coletividade. Assim, a atuação de uma equipe multidisciplinar torna-se essencial para que os resultados sejam eficazes e permanentes.

O Método do Arco contribuiu grandemente para a obtenção dos resultados, visto que exige que o pesquisador insira-se na realidade a ser estudada e instiga-o e aos participantes a buscar transformação nas situações consideradas problemáticas, sendo que cada família torna-se a principal protagonista das mudanças em sua história de vida.

\section{REFERÊNCIAS}

1. Brasil. Ministérios da Educação e da Saúde. Decreto $\mathrm{n}^{\circ}$. 6.286, de 5 de dezembro de 2007.Institui o programa saúde na escola - PSE, e dá outras providências [decreto na internet]. Diário Oficial da União 06 dez 2007 [acesso em 05 out 2011];Seção 1. Disponível em: < http://www.planalto. gov.br/ccivil_03/_ato2007-2010/2007/decreto/d6286.htm

2. Freire P. A Ação cultural para a liberdade. 5. ed. Rio de Janeiro: Paz e Terra; 1981.(O Mundo Hoje, v.10).

3. Ministério da Saúde. Escolas promotoras de saúde: experiências do Brasil. Brasília, DF: Ministério da Saúde; 2006. p.13-16.
4. Ministério da Saúde. Escolas promotoras de saúde: experiências do Brasil. Brasília, DF: Ministério da Saúde; 2006. p.9-12.

5. Schaurich D. Compreensões de acadêmicos de enfermagem sobre famílias: algumas reflexões. Esc Anna Nery Rev Enferm [periódico na internet]. 2009 [acesso em 22 set 2011];13(2):415-420. Disponível em: http://www. scielo.br/pdf/ean/v13n2/v13n2a25.pdf

6. Bordenave JD, Pereira AM. Estratégias de ensino e aprendizagem. 4. ed. Petrópolis: Vozes; 1982.

7. Berbel NAN. Metodologia da problematização: uma 
alternativa metodológica apropriada para o Ensino Superior. Semina Ciên Soc Hum 1995; 16(2):9-19.

8. Conselho Nacional de Saúde (Brasil). Resolução nº. 196, de 10 de outubro de 1996. Diretrizes e normas regulamentadoras de pesquisa envolvendo seres humanos. Diário Oficial da União 16 out 1996;Seção 1.

9. Ministério da saúde. Programa Nacional de Saúde Escolar: Despacho n. ${ }^{\circ}$ 12.045/2006 (2a ${ }^{\text {. }}$ série). Publicado no Diário da República n. ${ }^{\circ} 110$ de 7 de Junho [acesso em 28 mar 2012]. Disponível em: http://www.min-saude.pt/NR/rdonlyres/4612A602-74B9-435E-B7200DF22F70D36C/0/ProgramaNacionaldeSa \%C3\%BAdeE scolar.pdf

10. Schenker M, Minayo MCS. A implicação da família no uso abusivo de drogas: uma revisão crítica. Ciênc Saúde Coletiva [periódico na internet]. 2003 [acesso em 05 out 2011];8(1):299-306. Disponível em: http://www. scielo.br/scielo.php? pid = S1413-81232003000100 022\&script $=$ sci_arttext

11. Freire $T$, Tavares D. Influência da autoestima, da regulação emocional edogênero no bem-estar subjetivoe psicológico de adolescentes. Rev Psiquiatr Clín [periódico na internet]. 2011 [acesso em 07 de jun 2012];38(5):184-188. Disponível em: http://www.scielo.br/scielo.php?pid=S0101$-60832011000500003 \&$ script $=$ sci_arttext
12. Fujioka TR. Solidão na relação conjugal: um estudo fenomenológico. Goiânia. Dissertação [Mestrado em Psicologia] -Universidade Católica de Goiás; 2009.

13. Wagner A, Falcke D, Silveira LMBO, Mosmann CP. A comunicação em famílias com filhos adolescentes. Psicol Estud [periódico na internet]. 2002 [acesso em 07 jun 2012];7(1):75-80. Disponível em: http://www.scielo.br/ pdf/pe/v7n1/v7n1a08.pdf

14. Gomes MA, Pereira MLD. Família em situação de vulnerabilidade social: uma questão de políticas públicas. Ciênc Saúde Coletiva [periódico na internet]. 2005 [acesso em 07 jun 2012];10(2):357-363. Disponível em http:// www.scielo.br/pdf/csc/v10n2/a13v10n2.pdf

15. Reis $\mathrm{CB}$, Bernardes $\mathrm{EB}$. O que acontece atrás das grades: estratégias de prevenção desenvolvidas nas delegacias civis contra HIV/AIDS e outras doenças sexualmente transmissíveis. Ciênc Saúde Coletiva [periódico na internet]. 2011 [acesso em 07 jun 2012];16(7):3331-3338. Disponível em: http://www.scielo.br/pdf/csc/v16n7/32.pdf

16. Botti ML, Waidman MAP, Marcon SS, Scochi MJ. Conflitos e sentimentos de mulheres portadoras de HIV/AIDS: um estudo bibliográfico. Rev Esc Enferm [periódico na internet]. 2009 [acesso em 02 maio 2012];43(1):79-86. Disponível em: http://www.scielo.br/scielo.php?script=sci_artt ext\&pid $=$ S0080-62342009000100010 